University of Wollongong

Research Online

Faculty of Social Sciences - Papers (Archive) Faculty of Arts, Social Sciences \& Humanities

$1-1-2018$

Weed hygiene practices in rural industries and public land management: Variable knowledge, patchy implementation, inconsistent coordination

Nicholas J. Gill

University of Wollongong, ngill@uow.edu.au

Sonia Graham

University of New South Wales, sonia.graham@unsw.edu.au

Rebecca Cross

University of Sydney, rc894@uowmail.edu.au

Eli M. Taylor

University of New South Wales, elit@uow.edu.au

Follow this and additional works at: https://ro.uow.edu.au/sspapers

Part of the Education Commons, and the Social and Behavioral Sciences Commons

Research Online is the open access institutional repository for the University of Wollongong. For further information contact the UOW Library: research-pubs@uow.edu.au 


\title{
Weed hygiene practices in rural industries and public land management: Variable knowledge, patchy implementation, inconsistent coordination
}

\author{
Abstract \\ Weed management science and practice largely focuses on eradicating, containing and reducing existing \\ weed populations; the focus is on plants in situ. More recently, the redefinition of biosecurity to include \\ weeds has seen greater attention paid to preventing the introduction of weeds to previously uninfested \\ areas within countries. Thus weed hygiene has come to the fore, with a growing number of publications \\ recommending a diverse range of practices to minimise the spread of weeds across farm, regional and \\ state boundaries. Yet little is known about the uptake of weed hygiene practices. The aim of this paper is \\ to evaluate the extent to which best practice weed hygiene is being implemented on, across and along \\ private and public lands. Telephone interviews were conducted with 54 private and public land managers, \\ weed contractors, and agricultural transport operators in New South Wales, Australia. Vehicle hygiene \\ was commonly undertaken across all stakeholder groups when it was consistent with other goals, \\ requirements or norms. Other practices, such as sequencing harvesting from least to most weedy \\ paddocks or including weed hygiene clauses in contracts were often known, but rarely practiced because \\ of the onerous labour and financial costs or concerns about social etiquette. Individual commitment to \\ weed hygiene efforts were also undermined by intra and inter-organisational coordination challenges. \\ Public debate and assessment are needed on the benefits and costs to society of weed hygiene \\ compared to in situ weed control to determine where best to invest limited time and resources.

\section{Disciplines} \\ Education | Social and Behavioral Sciences

\section{Publication Details} \\ Gill, N., Graham, S., Cross, R. \& Taylor, E. (2018). Weed hygiene practices in rural industries and public land \\ management: Variable knowledge, patchy implementation, inconsistent coordination. Journal of \\ Environmental Management, 223 140-149.
}


Weed Hygiene Practices in Rural Industries and Public Land Management: Variable Knowledge, Patchy Implementation, Inconsistent Coordination

Nicholas Gill, Sonia Graham, Rebecca Cross, Eli Taylor

Nicholas Gill

School of Geography and Sustainable Communities, Australian Centre for Cultural Environmental Research

Faculty of Social Sciences

University of Wollongong NSW 2522 Australia

+61 24221 4165, ngill@uow.edu.au

ORCID: 0000-0001-7514-2837

Sonia Graham

School of Social Sciences

University of New South Wales NSW 2152 Australia

ORCID: 0000-0003-4195-4559

Rebecca Cross

Sydney Institute of Agriculture

University of Sydney, NSW, Australia

ORCID: 0000-0003-3582-5996

Eli Taylor

School of Social Sciences

University of New South Wales NSW 2152 Australia 


\begin{abstract}
Weed management science and practice largely focuses on eradicating, containing and reducing existing weed populations; the focus is on plants in situ. More recently, the redefinition of biosecurity to include weeds has seen greater attention paid to preventing the introduction of weeds to previously uninfested areas within countries. Thus weed hygiene has come to the fore, with a growing number of publications recommending a diverse range of practices to minimise the spread of weeds across farm, regional and state boundaries. Yet little is known about the uptake of weed hygiene practices. The aim of this paper is to evaluate the extent to which best practice weed hygiene is being implemented on, across and along private and public lands. Telephone interviews were conducted with 54 private and public land managers, weed contractors, and agricultural transport operators in New South Wales, Australia. Vehicle hygiene was commonly undertaken across all stakeholder groups when it was consistent with other goals, requirements or norms. Other practices, such as sequencing harvesting from least to most weedy paddocks or including weed hygiene clauses in contracts were often known, but rarely practiced because of the onerous labour and financial costs or concerns about social etiquette. Individual commitment to weed hygiene efforts were also undermined by intra and inter-organisational coordination challenges. Public debate and assessment are needed on the benefits and costs to society of weed hygiene compared to in situ weed control to determine where best to invest limited time and resources.
\end{abstract}




\section{Introduction}

Globally, minimising the spread of invasive plants by regulating and working with a wide range of individual and company landholders and land users, plant industries, and agencies is undertaken by all levels of government. This investment represents a significant part of land and natural resource management governance and expenditure. Landholders are, for example, often required to manage their land to mitigate the spread of designated invasive plants. More generally, a key element of biosecurity policy and management internationally is prevention of the entry and subsequent spread of invasive organisms (Food and Agriculture Organisation, 2007). Accordingly, prevention is a central plank of invasive plant policy and management (e.g. Great Britain Invasive Non-Native Species Strategy, the USA 2016-2018 National Invasive Species Council Management Plan, and the National Invasive Species Strategy and Action Plans of Jamaica, Mauritius, Tonga, Vanuatu, among others). Prevention can be enacted in numerous ways. Perhaps best known is border control and quarantine at ports and airports. However, both within countries and within and across boundaries at other scales - states, regions, individual properties, and public landholdings - what are generally known as 'weed hygiene' practices can play an important role in preventing and/or minimizing the further spread of invasive plants. These practices aim to reduce the spread of invasive plants and include cleaning vehicles, machinery and equipment, and taking precautions in fodder and animal transport. Yet, in Australia and elsewhere, this aspect of invasive plant (hereafter referred to as weeds) management appears to have attracted little research outside of that focussed on distribution vectors.

Among Australian weed managers, weed hygiene is regarded as an important part of weed management and this importance is reflected in the plethora of policies and guidelines on weed hygiene practices (Table 1). Despite the presence of such research and guidelines, the 2013 National Landcare Survey (de Hayr, 2013) indicated that very few resources were being expended on weed hygiene; only $11 \%$ of agricultural businesses surveyed incurred weed hygiene costs. More generally, 


\section{Table 1}

\section{Recommended Weed Hygiene Practices and Responsibility in Research and Management Sources}

\begin{tabular}{|c|c|c|c|}
\hline Location & Responsibility & Practice & Source \\
\hline \multirow[t]{9}{*}{ On-farm } & Farmers & $\begin{array}{l}\text { Sow weed-free seed: check Seed Analysis Certificate for bought seeds (or } \\
\text { request a Weed Hygiene Declaration); demarcate seed paddocks and ensure } \\
\text { weed numbers are very low }\end{array}$ & $\begin{array}{l}\text { (GRDC, 2014; PHA, } \\
\text { 2012) }\end{array}$ \\
\hline & & $\begin{array}{l}\text { Set aside containment areas if hand-feeding stock with imported feed; empty } \\
\text { out stock before returning to pasture }\end{array}$ & $\begin{array}{l}\text { (GRDC, 2014; Sindel } \\
\text { and Coleman, 2010, } \\
\text { 2012) }\end{array}$ \\
\hline & & $\begin{array}{l}\text { Harvest paddocks from least weedy to most weedy; clean farm machinery } \\
\text { before relocation }\end{array}$ & (GRDC, 2014) \\
\hline & & $\begin{array}{l}\text { Train farm personnel in biosecurity and farm hygiene practices; supply } \\
\text { personnel hygiene supplies where appropriate }\end{array}$ & (PHA, 2011, 2012) \\
\hline & & Secure loads (grain, fodder) if suspected of containing weed seeds & (Biosecurity \\
\hline & & & Queensland, 2014) \\
\hline & & $\begin{array}{l}\text { Avoid vehicle and machinery movements when road conditions are wet and } \\
\text { muddy; do not drive through infested paddocks; visiting consultants to use } \\
\text { vehicle supplied by farmer }\end{array}$ & $\begin{array}{l}\text { (ACCRC, 2000; } \\
\text { Biosecurity Queensland, } \\
\text { 2014) }\end{array}$ \\
\hline & $\begin{array}{l}\text { Farmers, } \\
\text { contractors }\end{array}$ & $\begin{array}{l}\text { Enforce machinery cleaning standards with all harvest, baling, windrowing } \\
\text { and grain transporting contractors }\end{array}$ & $\begin{array}{l}\text { (GRDC, 2014; PHA, } \\
\text { 2012) }\end{array}$ \\
\hline & $\begin{array}{l}\text { Farmers, } \\
\text { agricultural } \\
\text { transport } \\
\text { companies }\end{array}$ & $\begin{array}{l}\text { Quarantine livestock exposed to plants for 5-8 days prior to transport to a } \\
\text { new destination; use dedicated weed-free holding paddocks }\end{array}$ & $\begin{array}{l}\text { (DNRME, 2004; GRDC, } \\
\text { 2014) }\end{array}$ \\
\hline
\end{tabular}




\begin{tabular}{|c|c|c|c|}
\hline \multirow[t]{7}{*}{$\begin{array}{l}\text { On and off- } \\
\text { farm }\end{array}$} & \multirow[t]{5}{*}{$\begin{array}{l}\text { Farmers, } \\
\text { contractors }\end{array}$} & Vehicle/machinery wash-down and decontamination & $\begin{array}{l}\text { (ACCRC, 2000; } \\
\text { Anderson, 2011; }\end{array}$ \\
\hline & & \multirow{4}{*}{$\begin{array}{l}\text { There are specific procedures for cars, trucks, 4WDs; compactors; cotton } \\
\text { pickers; dump trucks; excavators; headers and harvesters; mini tractors; PTO } \\
\text { rotary hoes; track-type dozers; wheeled loaders; wheeled tractors }\end{array}$} & Biosecurity Queensland, \\
\hline & & & 2014; DoE, 2015; \\
\hline & & & DPIPW\&E, 2015; \\
\hline & & & Rudman et al., 2004) \\
\hline & $\begin{array}{l}\text { Contractors, field } \\
\text { workers }\end{array}$ & Personal and small tool wash-down using portable wash baths & (Rudman et al., 2004) \\
\hline & Field workers & $\begin{array}{l}\text { Ensure all materials taken onto a site (seedlings, mulch, soil, gravel, rock and } \\
\text { sand) are certified free of weeds (AS3743-2003, AS4454-2012) }\end{array}$ & (DPIPW\&E, 2015) \\
\hline \multirow[t]{7}{*}{$\begin{array}{l}\text { Roadsidel } \\
\text { construction } \\
\text { sites }\end{array}$} & \multirow[t]{7}{*}{$\begin{array}{l}\text { Roadside } \\
\text { managers, } \\
\text { contractors }\end{array}$} & $\begin{array}{l}\text { Conduct site assessment to determine if noxious weeds or plant disease are } \\
\text { present; chemically treat or manually remove weeds before commencing } \\
\text { work; plan disposal method to be used }\end{array}$ & $(\mathrm{CCF}, 2011)$ \\
\hline & & $\begin{array}{l}\text { Minimise movement of machinery and avoid slashing during peak seed } \\
\text { production times }\end{array}$ & $\begin{array}{l}\text { (Baldyga, 2006; } \\
\text { Biosecurity Queensland, } \\
\text { 2014; CCF, 2011) }\end{array}$ \\
\hline & & Undertake works in clean areas then gradually work toward infested areas & (Baldyga, 2006) \\
\hline & & Incorporate machinery hygiene into contracts & (Baldyga, 2006) \\
\hline & & $\begin{array}{l}\text { Ensure roadside material, such as soil and gravel, is seed-free (vendor } \\
\text { declaration); locate stockpiles in weed-free areas and regularly inspect }\end{array}$ & $\begin{array}{l}\text { (Baldyga, 2006; CCF, } \\
\text { 2011) }\end{array}$ \\
\hline & & $\begin{array}{l}\text { Locate staging grounds (work depots) in weed-free areas; undertake regular } \\
\text { inspections and control works }\end{array}$ & (Baldyga, 2006) \\
\hline & & Nominate areas for clean-down procedures and roadside slashing, and & (Baldyga, 2006; CCF, \\
\hline
\end{tabular}




\begin{tabular}{|c|c|c|c|}
\hline & & $\begin{array}{l}\text { establish wash-bay for long-term projects; include on site plan; avoid } \\
\text { sensitive vegetation and wildlife; ensure run-off will not enter any watercourse } \\
\text { (30m buffer) }\end{array}$ & 2011; DPIPW\&E, 2015) \\
\hline & & Avoid scalping and tyre rutting & (Baldyga, 2006) \\
\hline $\begin{array}{l}\text { Waterways, } \\
\text { wetlands, } \\
\text { riparian } \\
\text { zones and } \\
\text { boggy areas }\end{array}$ & $\begin{array}{l}\text { Field workers, } \\
\text { contractors }\end{array}$ & $\begin{array}{l}\text { Avoid use of felt-soled boots, waders } \\
\text { Check all equipment is free of debris and dry } \\
\text { Check all machinery (tractors, mowers, slashers, bulldozers, graders, } \\
\text { excavators), vehicles, boats, trailers are clean and dry } \\
\text { Disinfect (with Phytoclean or F10) footwear, equipment, vehicles and } \\
\text { machinery between sites; wait } 48 \text { hours before using equipment in another } \\
\text { waterway }\end{array}$ & $\begin{array}{l}\text { (Allen and Gartenstein, } \\
\text { 2010) }\end{array}$ \\
\hline
\end{tabular}


there has been limited research into the extent to which weed hygiene is being undertaken by landholders and other groups with land and weed management roles, and particularly into the reasons behind implementation, or lack thereof. Thus, the aim of this paper is to explore the extent to which private landholders, public land managers, weed contractors and agricultural transport operators know about and implement weed hygiene best practices. It also examines the reasons why they do or do not implement certain practices. It is based on research in New South Wales (NSW), located in southeastern Australia.

\section{Weed Hygiene in Policy and Research}

Pimentel et al. (2005) estimated that invasive species caused \$US120 billion in damage and losses in the United States. High figures are similarly reported for other countries such as China (Pejchar and Mooney, 2009). In Australia, a conservative estimate is that weeds cost the NSW economy over \$AUS1.8 billion each year through control costs, productivity losses, public agency expenditure, and value lost due to price responses in agricultural markets (Natural Resources Commission, 2014). This does not include impacts on biodiversity or costs of control by private landholders on non-agricultural land. More generally in Australia, the recent draft Australian Weeds Strategy 2017 to 2027 (Invasive Plants and Animals Committee, 2016) noted that weeds cost the grains industry \$AUS3.27 billion annually in control measures and lost production. Hoffmann and Broadhurst (2016) calculated that the total costs of invasive species in Australia in 2011-12 were \$AUS13.6 billion and noted that this is a conservative estimate, especially for environmental costs.

In this context, there is emphasis in policy in prevention of weed spread at various scales. For this paper, the focus is on prevention of spread within national borders. In Australia, the scope of appropriate strategies and management tools is largely governed by the extent to which a weed is widespread. Once a weed is widespread and abundant through its potential range, asset-based protection is the primary approach. Prior to this point management is guided by prevention, eradication, and containment strategies at 
various scales (Invasive Plants and Animals Committee, 2016). Weed hygiene refers to activities at scales ranging from the nation down to individual properties informed by prevention, eradication, or containment strategies. The nominal cost-benefit ratios for investment in weed management activities for these stages are, respectively, 1:100, 1:25, and 1:5-10 (Western Australian Agriculture Authority, 2016). In contrast, the nominal ratio for asset-based protection for widespread weeds is $1: 1-5$. If these figures hold, it seems likely that investing in weed hygiene practices is worthwhile and will assist in reducing the agricultural and environmental costs associated with weeds in Australia and elsewhere.

\subsection{Weed hygiene policy}

The policy interest in weed hygiene is evident in various ways. It is emphasized in goals and priorities of the recent draft Australian Weeds Strategy (Invasive Plants and Animals Committee, 2016). In the past, the National Weed Spread Prevention draft action plan (National Weed Spread Prevention Committee, 2006) had agreed bestpractice hygiene and spread prevention guidelines, standards, protocols, and codes of practice among its deliverables. The National Weeds Program sponsored a project to improve and coordinate national efforts to reduce weed spread (Barker 2005). More generally, as the sources in Table 1 show, there has been a plethora of work by agencies, industry bodies, and research organisations to identify and promote weed hygiene practices.

Paradoxically, despite this apparent significance, weed hygiene remains somewhat elusive in Australian policy and practice. For example, it appears that the National Weed Spread Prevention draft action plan was never finalised or approved. In terms of recent state policy neither the NSW Biosecurity Strategy 2013-2021 (Department of Primary Industries, 2013) nor Victoria's Biosecurity Implementation Plan (Department of Environment and Primary Industries, 2010), directly address weed hygiene. Queensland's Biosecurity Strategy (2009-2014; Department of Primary Industries and Fisheries, 2008) mentions wash-down areas to prevent spread of weed seeds and Western Australia's Biosecurity Strategy 2016-2025 (Western Australian Agriculture 
Authority, 2016) mentions wash down of camping, hiking and boating vehicles and equipment as examples of prevention but do not otherwise discuss weed hygiene in any detail. In NSW, the Natural Resources Commission had conducted a review of weed management in the year preceding this research project and hygiene was only briefly mentioned three times in the final 181-page report (Natural Resources Commission, 2014). It is not clear as to why there is this apparent mismatch between apparent significance and follow-up, and the sometimes simultaneous presence and absence of weed hygiene in policy and policy implementation - research into this area of biosecurity policy and practice would be valuable.

\subsection{Weed hygiene research}

There has been considerable research on pathways for weed dispersal. This work has identified six principal and general pathways involving varying degrees of human involvement: release, escape, containment, stowaway, corridor and unaided (Hulme et al., 2008). More specifically, Coleman et al. (2011) identified high risk pathways for weed spread that include the ornamental plant trade, machinery and vehicles, and trade in fodder plants and agricultural produce. This mirrors other research that demonstrates the significance of animal, human, and machinery movement between, and on, rural properties, in dispersing weed seeds (Bajwa et al., 2018; Blanco-Moreno et al., 2004; Gardener et al., 2003; Nikman et al., 2002; Secomb, 2006). It has also been shown that public land management vehicles and machinery can carry significant amounts of weed seeds (Moerkerk, 2006). Tourism and recreation activities are also considered to be a major pathway for weed spread, including boating and angling, horse-riding, mountain biking, off-road driving, and hiking (Anderson et al., 2015; Ansong and Pickering, 2014; Ansong et al., 2015; Lonsdale and Lane, 1994; Pickering et al., 2011; Weiss et al., 2016).

Practices and attitudes relating to weed hygiene are, however, rarely covered in weed hygiene research, nor are they discussed in social science weed research (see for instance Cattanach et al., 2013; Davis and Carter, 2014; Graham, 2013; Grech et al., 2014; Klepeis et al., 2009; Reeve et al., 2015). Moreover, weed hygiene practices are 
typically not included in discussions of weed control strategies (see for instance Chalak and Pannell, 2012; Van Der Meulen et al., 2007). Nor do they tend to be covered in integrated weed management research, which, while characterised by a long list of onfarm practices, tends not to include weed hygiene practices (see for instance Huwer et al., 2005; Llewellyn et al., 2004, 2007). This absence is paralleled in the Australian Bureau of Statistics (2008) survey of natural resource management on farms which asked a number of questions about weed control but did not ask about hygiene.

To the extent that attitudes and practices have been examined, a review of Australian social science research on weeds (Aslin et al., 2013) showed that little information is available on hygiene practices in such research. The limited research that does exist shows that knowledge and use of weed hygiene practices among landholders can be low for many practices and variable among landholder groups. For example, Sindel et al. (2013) and Ruttledge et al. (2015) both found that knowledge or use of stock quarantining techniques to minimise weed spread are relatively low among landholders.

Some government sources provide further insights into the knowledge and use of weed hygiene practices. The 2013 National Landcare Survey (de Hayr, 2013) found that 89\% of farmers did not incur any costs for weed hygiene. Despite the fact that some weed hygiene practices are no or low cost, this suggests that that a low proportion of farmers are engaging in weed hygiene. Finally, the Strategic Analysis and Scoping Study on Human Spread of Weeds (Barker, 2005) showed that managers perceive that many laws, policies, and programs that have a role in controlling weed spread are only 'slightly effective' or that there is insufficient information to know if they are effective.

Despite strong legislation around weed hygiene and a biosecurity framing around weed management (Hinchliffe and Bingham, 2008), there is a relatively poor understanding of weed hygiene practices in the academic and grey literature. While the pathways for weed spread are understood, and there are many policies and guidelines on weed hygiene practices sectors, there is relatively little known about rural landholders' weed hygiene practices and particularly their reasons for adoption or non-adoption. There is even less known for other groups that potentially have a role in weed dispersal, such as 
public land managers, contractors, and agricultural transport companies. This absence can be compared to more extensive research into on-farm biosecurity regarding animal diseases and the knowledge, beliefs, and practices of farmers and other actors such as vets. Such research, particularly in the UK paints a complex picture of actors' views of their role, of the causes and loci of responsibility of disease spread and management, and of their agency in adequately addressing biosecurity issues (see, for example Sayers et al., 2014). However, this research into biosecurity tends to attribute nonadoption to a lack of knowledge about biosecurity practices (Heffernan et al., 2008; Sayers et al., 2014) or to poor knowledge transfer about the efficacy and economic benefits (Gunn et al., 2008). However, weed management social science shows that knowledge and communication are not necessarily the most significant or only influences on weed management (Head, 2017). As well as economic factors, practice is influenced by a range of social and cultural factors including social norms (Ma et al., 2018; McKiernan, 2017), trust (Graham, 2014), divergent views about plant belonging that do not neatly accord to the native/non-native distinction (Cooke and Lane, 2015), and pragmatic decisions about living with and tolerating weeds in various ways (Head et al., 2015).

\section{Methods}

To determine levels of awareness and implementation of weed hygiene practices, a benchmarking survey was devised with practices tailored to different actors targeted by this study. As there is no agreed-upon set of best practices which define weed hygiene, Australian and International industry policies and guidelines were reviewed to develop a comprehensive list of weed hygiene practices (Table 1).

The survey was delivered as part of 54 telephone interviews between November 2015 and March 2016 with various actors across rural NSW who have regular contact with weeds and strong potential to spread weeds. These actors included private landholders (both graziers and croppers; $n=17$ ), public land managers (including local council weeds officers and in-house weed controllers; $n=15$ ), weed contractors (contracted by private 
and public land managers and landholders to manage weeds; $n=12$ ), and agricultural transport operators (who transport mainly grain and livestock from rural properties) $(n=10)$. In total, 115 people were contacted from target groups. Approximately 18 contacts refused an interview outright for varying reasons including lack of time and not wanting scrutiny; 11 of these were contractors and transport operators. There was a geographic spread of participants from across NSW with respondents from most Local Land Service (LLS) regions_-LLS is the lead organisation for regional strategic weed management plans in NSW (Local Land Services, 2017). A disproportionately large number of participants were from the South-East LLS: 28 percent of respondents were from this region. There was a limited response from some regions, particularly the Greater Sydney and Northern Tablelands LLS and no response from the Western LLS, so our survey results are biased to those operating in higher rainfall, coastal landscapes

Given the paucity of knowledge regarding weed hygiene practices, the exploratory goals of this research, and the range of actors targeted, potential participants were identified using purposeful sampling strategies working through the contacts of a project steering committee, interviewee chain referral, and through company websites and public business directories. Such strategies aim to recruit 'cases' or participants that fit required criteria (e.g. are public land managers with weed management responsibilities) and are likely to yield insights and deeper understanding rather than generalisability per se (Patton, 2002). Private landholders and public land managers were the most accessible while weed contractors and transport companies were difficult to access and it was harder to secure their participation. This is reflected in the lower numbers in these categories. For these reasons, and despite using resources such as business directories, it is possible that participants are relatively cognisant of, and active in, weed hygiene and underrepresent the views of actors outside of the networks used to recruit respondents.

Respondents were asked a series of open and closed response questions about weeds, weed control and weed hygiene (Graham et al., 2016). For implementation of weed hygiene practices, they were asked if they always, very often, sometimes, rarely, or never implemented a practice. The open questions yielded qualitative responses that 
identified the role of the participant in weed management and garnered their views on the importance of weed hygiene, their motivations for practising weed hygiene as well as issues that prevent implementation of practices, their experience with weed hygiene training and their knowledge of successful weed hygiene campaigns. Interviews were recorded and transcribed and the qualitative data thematically analysed (Braun and Clarke, 2006) using the NVivo software. While quantitative responses gauged the extent of participant knowledge and implementation of known weed hygiene practices in this paper the focus is on the qualitative results, drawing on a summary of the quantitative data to highlight key themes that are also evident through analysis of the qualitative data. Tables 2 and 3 contain quotes from the interviews that are 'illustrative' (Neale, 2016, p.1104) of the analytical themes from the interviews in order to show how 'meanings are expressed in the respondents' own words' (Baxter and Eyles, 1997, p.508) and to demonstrate the credibility and consistency of the analysis (Korstjens and Moser, 2018; Lincoln and Guba, 1985; Neale, 2016).

\section{Results}

\subsection{Who does weed hygiene?}

This section contains the key points from the quantitative data which are consistent with the qualitative analysis. More detailed quantitative results and discussion are available in Graham et al. (2016) and in a supplementary data table that summarises this data.

For all interviewee groups, the most commonly implemented weed hygiene practices were those that were likely to be done for other reasons. These practices included the use of wash bays to wash down vehicles and machinery, conforming to stock and seed movement and sale regulations, and checking that machinery was clean. Overall, the practices that were least likely to be implemented included the use of wash baths to wash down boots, clothing and tools, as well as including weed hygiene clauses in contracts, and training staff in weed hygiene. 
For private landholders and public land managers, the clearest gap between knowledge and implementation was between relatively good knowledge of including weed hygiene clauses in contracts and low use of such requirements. For public land managers, who had high levels of knowledge of weed hygiene, the gap between knowledge and implementation particularly included the use of wash baths and wash bays for contractors' vehicles and machinery. Weed hygiene knowledge and implementation was comparable for contractors who were generally knowledgeable but also inconsistent in implementation, with wash bath use, clauses in contracts, and, to a lesser extent, vehicle and machinery cleaning not used to the extent that knowledge might suggest. Private landholders were also relatively unaware that some practices, such as restricting farm access or limiting vehicle and machinery movement during wet periods, effectively constituted weed hygiene practices. Such practices might also be undertaken for other reasons such as insurance and road protection. Transport operators' knowledge and implementation generally reflected these patterns. They had high levels of implementation of washing and checking vehicles and machinery, and low levels of wash bath use, training staff, and using weed hygiene clauses in contracts. However, their levels of knowledge were low for a number of relevant practices and half did not think that weed hygiene was important for their operations, Further, seven of the ten transport operators interviewed indicated that landholders did not request that they meet hygiene standards or undertake weed hygiene activities.

\subsection{Why do weed hygiene?}

The quantitative results show that while knowledge is generally good, implementation is patchy across and within interviewee groups. Qualitative interview data provides insight into the reasons why weed hygiene practices are or are not implemented.

\subsubsection{Reasons for conducting weed hygiene}

Across all interviewee groups it was clear that weed hygiene practices were undertaken most where they were consistent with other goals, tasks, requirements, or norms (Table 2). The most common practice was washing or blowing down vehicles and equipment. While some landholders specifically cleaned vehicles and equipment for weed hygiene 
reasons, it was more common for landholders to talk about such practices as being for other reasons: "we wash down vehicles but not because of hygiene... just to keep them clean and just to keep them tidy" (Private Landholder). Similar consistency was found for other weed hygiene practices, such as restricting access to properties, which landholders said they did largely for security and/or insurance purposes.

Washing down vehicles was the most common task undertaken by transport operators who are required to do so as part of general maintenance and/or between transporting different materials. For such operators, meeting standards and requirements was also a driver of weed hygiene practices. A private landholder who transported his own grain and who was influenced by buyers' quality requirements, noted that he doesn't "get paid for delivering weed seeds". Similarly, a transport operator cited industry standards as influencing his firm's practices in relation to cleaning storage facilities as well as vehicles (Table 2).

Weed hygiene was also carried out where professional norms and reputation aligned with weed hygiene. Interviewees said that they cleaned borrowed equipment out of courtesy rather than for weed hygiene per se and weed contractors were concerned about their reputation and professional practice (Table 2). Similarly, some public land managers were acutely aware of the significance of public perception of their work, arguing that their reputation depended being seen to demonstrate best practice and to be methodical in weed hygiene practice (Table 2)

Interviewees who perceived that weed hygiene practices represented an investment that would alleviate future costs or problems also actively undertook weed hygiene. This was particularly evident among private landholders and public land managers, two groups where costs and responsibility for weed management are directly felt. A public 
Table 2

Reasons and Themes Associated with Undertaking Weed Hygiene

\begin{tabular}{ll}
\hline $\begin{array}{l}\text { Reason/Analytical } \\
\text { Theme }\end{array}$ & Action \\
\hline $\begin{array}{l}\text { Consistency with } \\
\text { other tasks or }\end{array}$ & $\begin{array}{l}\text { Wash/blow } \\
\text { down vehicles } \\
\text { goals }\end{array}$ \\
$\begin{array}{l}\text { and machinery, } \\
\text { restrict access }\end{array}$
\end{tabular}

Illustrative Quotes

If we know we've got a trouble weed somewhere we will blow our gear off as we shift paddocks... and then we'll give it a wash. Our header gets blown down every morning. We have got one spot where we wash our vehicles all the time... it's not on dirt, it's on a hard granite base, so nothing grows there (Private Landholder).

\begin{tabular}{|c|c|c|}
\hline $\begin{array}{l}\text { Meeting } \\
\text { standards or } \\
\text { requirements }\end{array}$ & $\begin{array}{l}\text { Cleaning } \\
\text { transport } \\
\text { vehicles and } \\
\text { storage facilities }\end{array}$ & $\begin{array}{l}\text { Our storage facilities are an important part of our } \\
\text { business. Our customers depend on us to deliver } \\
\text { a clean product...we have to meet the Grain } \\
\text { Trade Australia standards for weed seeding } \\
\text { (Transport Operator). }\end{array}$ \\
\hline $\begin{array}{l}\text { Alignment of } \\
\text { professional } \\
\text { norms and } \\
\text { reputation }\end{array}$ & $\begin{array}{l}\text { Wash down } \\
\text { vehicles and } \\
\text { equipment }\end{array}$ & $\begin{array}{l}\text { [I] make sure [the trucks are] all good before I go } \\
\text { to any other jobs. I'd feel guilty if I dragged } \\
\text { something onto someone else's property" (Weed } \\
\text { Contractor). }\end{array}$ \\
\hline $\begin{array}{l}\text { Demonstration of } \\
\text { good practice }\end{array}$ & $\begin{array}{l}\text { Wash down } \\
\text { vehicles and } \\
\text { equipment }\end{array}$ & $\begin{array}{l}\text { [If] someone believes rightly or wrongly...that } \\
\text { we've brought seed onto their property or we } \\
\text { haven't acted in a thorough methodical method } \\
\text { then that's obviously going to be bad...for our } \\
\text { reputation (Public Land Manager). }\end{array}$ \\
\hline $\begin{array}{l}\text { Prevent future } \\
\text { costs }\end{array}$ & $\begin{array}{l}\text { Wash down } \\
\text { vehicles and } \\
\text { equipment, be } \\
\text { persistent }\end{array}$ & $\begin{array}{l}\text { Every time I think I might be getting a bit slack on } \\
\text { it I just remind myself well, if I don't do this, the } \\
\text { actual cost of cleaning down the machinery now } \\
\text { is minimal compared to the cost that could be } \\
\text { (Private Landholder). }\end{array}$ \\
\hline $\begin{array}{l}\text { Undertake } \\
\text { straightforward } \\
\text { and low cost } \\
\text { actions }\end{array}$ & $\begin{array}{l}\text { Use weed apps, } \\
\text { clean vehicles } \\
\text { and equipment, } \\
\text { quarantine stock }\end{array}$ & $\begin{array}{l}\text { It's very easy to do; stock arrives and you } \\
\text { quarantine it in the yards for a day or two (Private } \\
\text { Landholder). }\end{array}$ \\
\hline $\begin{array}{l}\text { Intra-organisation } \\
\text { coordination }\end{array}$ & $\begin{array}{l}\text { Embed } \\
\text { practices and } \\
\text { protocols across } \\
\text { organisations } \\
\text { and systems for } \\
\text { operational staff }\end{array}$ & $\begin{array}{l}\text { We have toolbox meetings with our roadwork } \\
\text { operators... they've got rules they have to abide } \\
\text { by...[We] try to make sure that is a continuous } \\
\text { practice in the council (Public Land Manager). } \\
\text { They put in place a Red Guide Post Scheme and } \\
\text { they put that all up and down the highways } \\
\text { (Public Land Manager) }\end{array}$ \\
\hline $\begin{array}{l}\text { Inter-organisation } \\
\text { co-ordination }\end{array}$ & $\begin{array}{l}\text { Coordinating } \\
\text { and cooperating } \\
\text { on agency work } \\
\text { programs }\end{array}$ & $\begin{array}{l}\text { I'm in contact with the Roads and Maritime } \\
\text { Services [RMS] constantly. I go with them on joint } \\
\text { inspections...I've brought all the other agencies } \\
\text { to the table... The RMS now sends out their entire } \\
\text { annual work calendar to every shire in the state } \\
\text { (Public Land Manager) }\end{array}$ \\
\hline
\end{tabular}


land manager expressed this in terms of an already difficult job, "The job's already hard enough without making it harder by...spreading more weeds". Nonetheless, even for those who practised weed hygiene for this reason, persistence was something that needed to be worked at (Table 2).

Related to this reason, was the common theme that interviewees undertook practices that are relatively easy to do and/or are low cost. Providing and carrying weed identification guides (or using apps) and washing vehicles and equipment fall into this category (but see below), as does quarantining stock, which some landholders saw as a cost-effective and easy thing to do. Many private graziers explained that this was standard procedure with new stock and was motivated by disease prevention rather than weed hygiene, although this was recognised as a secondary benefit.

Finally, some interviewees brought up the issue of intra and inter-organisation coordination. While, this was most commonly seen as a problem and is discussed below, some instances of what was perceived as successful coordination were discussed. Interviewees talked of success being the result of three factors. First, there was an effort within organisations to establish protocols and embed weed hygiene practice across different sections of an organisation. For one council, this mean regular meetings with operational staff, and rules and systems regarding cleaning vehicles and clothing, as well as machinery movements along roadsides (Table 2).

Second, as part of such efforts, interviewees spoke of the need for clear and consistent systems to alert road workers and others to problematic areas where they needed to take action to avoid weed spread. The recently established Red Guide Post strategy in the Riverina and Central West of NSW (http://www.riverinaweeds.org.au/rgp/) was cited as a good example of such a scheme whereby red posts along roadsides tell slasher operators where they need to lift their cutting decks to avoid picking up weed seeds (Table 2).

Other interviewees explained that the success of this program also lay in its public marketing and education strategy whereby the scheme was promoted at local petrol stations and in talks on the significance of weed hygiene in local schools. 
As noted by several interviewees, an advantage of such actions is that they can mitigate against weed hygiene being dependent on motivated individuals, or 'personalities' as they put it. That said, a third element to enhance the potential for successful coordination was having someone to drive coordination within and across organisations and who was willing to constantly follow up and make weed hygiene an issue. This was particularly something that council weed officers took it upon themselves to do. For example, one council weeds officer established close lines of communications and associated actions with agencies whose work, such as road maintenance, and fire and land management requires good weed hygiene (Table 2).

Finally, qualitative responses elicited the finding that the most common reason for implementing weed hygiene practices was to tackle the onset (or prevent infestation) of a new weed or tenacious weed rather than to manage more commonly found and geographically dispersed noxious weeds.

\subsubsection{Reasons for not conducting weed hygiene}

Interviewees also identified barriers to implementation. These barriers can be labelled in terms of costs relative to other priorities and perceived benefit, lack of coordination, practicality and convenience, social pressure, and an absence of requirements for weed hygiene (Table 3).

In contradiction to the common view that weed hygiene represents a good investment of time and resources, was the view that weed hygiene simply was not or could not be a priority among the other demands of a farm or land management. For public agencies as well, with tight budgets and significant areas of land to manage, weed hygiene readily slips off the list of priorities. This view also resonated with public land managers, some of whom find it difficult to engender support and resourcing for weed hygiene when the problem and consequences are not readily apparent or visible. 
Table 3

Reasons and Themes Associated with not Undertaking Weed Hygiene

\begin{tabular}{|c|c|c|}
\hline $\begin{array}{l}\text { Reason/Analytical } \\
\text { Theme }\end{array}$ & Issues/Barriers & Illustrative Quotes \\
\hline $\begin{array}{l}\text { Insufficient } \\
\text { benefits }\end{array}$ & $\begin{array}{l}\text { Competing and/or } \\
\text { more immediate } \\
\text { priorities, lack of } \\
\text { resources, can } \\
\text { undertake weed } \\
\text { control as and when } \\
\text { needed }\end{array}$ & $\begin{array}{l}\text { I'm aware of the importance of all these } \\
\text { things, but I'm prepared to wear the } \\
\text { consequences...I know what the weeds are, } \\
\text { I know how to identify them, I know what the } \\
\text { agronomic practice required to.... control the } \\
\text { weeds are, and I'm prepared to do that in } \\
\text { lieu of the fact that my farm hygiene per se } \\
\text { isn't at optimum. (Private Landholder) }\end{array}$ \\
\hline $\begin{array}{l}\text { Impractical or } \\
\text { inconvenient }\end{array}$ & $\begin{array}{l}\text { Location of wash } \\
\text { down facilities, weed } \\
\text { seed removal difficult } \\
\text { in practice, lack of } \\
\text { resources, farm work } \\
\text { logistics and } \\
\text { demands }\end{array}$ & $\begin{array}{l}\text { No, they just harvest in order of ease of } \\
\text { management and sequence of moving } \\
\text { equipment and so on because we're not } \\
\text { going to go bouncing around from } 10 \\
\text { kilometres away to back to here just to } \\
\text { harvest different paddocks, (Private } \\
\text { Landholder). }\end{array}$ \\
\hline $\begin{array}{l}\text { Lack of intra and } \\
\text { inter- } \\
\text { organisational } \\
\text { coordination }\end{array}$ & $\begin{array}{l}\text { Public/private } \\
\text { boundaries, multiple } \\
\text { actors, } \\
\text { organisational silos, } \\
\text { lack of awareness, } \\
\text { lack of shared norms }\end{array}$ & $\begin{array}{l}\text { It's right-hand, left-hand. We had an } \\
\text { infestation of African lovegrass. It was } \\
\text { quarantined, fenced and signs went up. } \\
\text { Council mowing staff removed the tape...to } \\
\text { get in to do what they usually do...not even } \\
\text { general awareness of what other staff } \\
\text { members within the same organisation are } \\
\text { trying to achieve (Weed Contractor). }\end{array}$ \\
\hline $\begin{array}{l}\text { Not imposing } \\
\text { restrictions or } \\
\text { contractual } \\
\text { reauirements }\end{array}$ & $\begin{array}{l}\text { Shortage of } \\
\text { contractors, socially } \\
\text { awkward and social }\end{array}$ & $\begin{array}{l}\text { If we make our provisions too onerous we } \\
\text { don't get the contractor's return work. (Public } \\
\text { Land Manager). }\end{array}$ \\
\hline
\end{tabular}

requirements norms in rural

There might even be a bit of peer pressure... when you've got to meet that local contractor at the school [parents] association... the tennis club or whatever you're into... it's a small community thing (Private Landholder).

\begin{tabular}{ll}
\hline $\begin{array}{l}\text { Norms among } \\
\text { landholders }\end{array}$ & $\begin{array}{l}\text { Weed hygiene not } \\
\text { seen as mainstream } \\
\text { practice }\end{array}$
\end{tabular}

We did a... workshop at a nearby farm and they had signs on the gate saying, 'biosecurity area' and 'wash down space' and I tell you what. Pretty much all of the farmers who went [said], "Get real, what are you on about?" (Private Landholder)

\begin{tabular}{ll}
\hline Inconsistent & Requirements \\
application of & applied differently \\
weed hygiene & across contractors \\
requirements & and operators on \\
& farms
\end{tabular}
We were driving around the paddocks, on the farms, picking up the grain - seeds could be up in your radiator or on your chassis of your truck - but no one checked us but they always checked the contract harvesters (Transport Operator) 
A related, and potentially significant, view was that the benefits of weed hygiene were not sufficient, nor certain enough, to invest much in it - one landholder, for example, took this view, noting that they were confident in managing weeds as they occurred (Table 3). As well, many weed hygiene practices were seen as simply impractical or significantly inconvenient. There was a variety of issues linked to this theme including the location of wash down facilities, the difficulty of removing weed seeds from vehicles and equipment, the time and resourcing needed for public land managers to validate contractor compliance with requirements, and farm work patterns, including harvesting in which farmers are driven by logistics or crop readiness rather than paddock 'weediness' (Table 3). For most private landholders, restricting their movements during wet and muddy periods or at peak seed production times was impractical and incompatible with necessary day-to-day land management.

While there were positive examples of coordination as previously discussed, more common was the view that intra and inter-organisational coordination was lacking and a major barrier to effective landscape-scale weed hygiene. Interviewees commonly spoke of the difficulties of trying to get different organisations such as government agencies, utility companies, and contractors to undertake weed hygiene as they moved along roads, and through and between private and public properties in the course of their work. Within councils in particular, but also in other public organisations, the lack of coordination, awareness, and shared norms between different sectors was a common problem, with the result that different sections would undermine the work of others as they carried out their tasks (Table 3).

Some private and public land managers said that social constraints or norms around what is reasonable to ask of people constrained implementation of weed hygiene practices. This primarily manifested itself in two ways (Table 3). One related to the difficulties of finding contractors to undertake work. The second, in circumstances where there is plenty of work for contractors, was when landholders and managers were reluctant to contractually require them or ask them to undertake weed hygiene for fear of not being able to retain their services. Another landholder, who said he was 'thrilled' if he simply managed to get a contractor to his property, noted social constraints that can 
arise in relatively small communities. Related to this issue, there was some evidence that norms about behaviour also influenced adherence to weed hygiene guidelines, such as farmer's responses to weed hygiene facilities and requests at an on farmworkshop (Table 3).

Finally, and indirectly, a reluctance was discernible among landholders and public land managers to contractually require weed hygiene practices in the quantitative and qualitative data obtained from transport operators. Transport operators indicated that they were not asked by their clients to undertake weed hygiene. One operator who had previously transported grain and had been required to practice weed hygiene was not required to do it for livestock. This same interviewee also noted that when he had been transporting grain, requirements for weed hygiene were uneven (Table 3)

Collectively, the survey data and the interview results show that while weed hygiene can be done well and often is, it is facilitated by certain circumstances such as consistency with other goals and effective coordination. Where these circumstances are absent to some extent, such as where weed hygiene is inconvenient, where organisational practice or norms do not sufficiently encompass weed hygiene, or where it is simply not asked of people, implementation of weed hygiene is patchy, even when knowledge is adequate.

\section{Discussion}

Past research into on-farm biosecurity attributes non-adoption to lack of knowledge about biosecurity practices (Heffernan et al., 2008; Sayers et al., 2014) or poor knowledge transfer about the efficacy and economic benefits (Gunn et al., 2008). In this study, there were two key reasons why weed hygiene was not undertaken. For a small number of practices, there was a lack of knowledge, with some groups tending to be more knowledgeable than others; public land managers and transport operators were, respectively, the most and least knowledgeable. For other practices, there was a 'gap' between knowledge and values on the one hand, and behaviour on the other. The 
practices that were adopted exhibited a strong alignment between knowledge, values and implementation, and had non-biosecurity benefits as well.

\subsection{Knowledge deficit}

There was little consistency across groups with regards to the practices they were not knowledgeable about. The most knowledgeable groups overall were public land managers and weed contractors. For the public land managers there was no appreciable knowledge deficit. This is important given that staff of government agencies are key sources of advice for farmers about weed eradication and control (D'Emden et al., 2004) and could be important sources of advice for weed hygiene. The practice weed contractors were least knowledgeable about was avoiding wearing felt-soled boots and waders in waterways. This appears to be a genuine knowledge deficit. While such boots are banned in some US states and in NZ on biosecurity grounds, only one set of guidelines that recommend avoiding this practice was located (Allen and Gartenstein, 2010). Hence, further dissemination of this information of this practice to weed contractors may be worthwhile.

Landholders were least likely to know that restricting access to the farm constituted weed hygiene; some landholders implemented the practice for security and insurance reasons. This was just one of several weed hygiene practices landholders knew about, but did not perceive to be a form of weed hygiene. Other practices included keeping records of seed and sources and obtaining vendor declarations for new stock, which were done for legal reasons, disease and quality control. This suggests that further research is required to understand how landholders define weed hygiene and how it intersects with their other farm practices.

Many agricultural transport operators did not know about several weed hygiene practices that applied to them. This is consistent with other research on the biosecurity practices of auxiliary industries (Gunn et al., 2008). Here, it was also found that transport operators were the least likely to believe that weed hygiene is important for their businesses and that those who were undertaking weed hygiene practices, did so to be compliant with national grain trade standards. This suggests, that one way to 
encourage greater awareness, and uptake, of weed hygiene among the transport industry would be through the introduction of national guidelines and/or standards, and potentially through integrating weed hygiene into existing standards.

\subsection{Knowledge-implementation gap}

The practices that exhibited the largest gap between knowledge and implementation across the groups included the use of wash baths for equipment, clothes and footwear. This is consistent with other research of on-farm animal biosecurity practices, which have found that few landholders provide tubs for feet washing (Lestari et al., 2011) and that farm personnel and farm visitors are unlikely to use a footbath (Dorea et al., 2010), with the exception of veterinarians and inseminators (Hoe and Ruegg, 2006). Similarly, other research has found that washing tyres before entering a property is infrequently done (Dorea et al., 2010) and Heffernan et al. (2008) found that only $3 \%$ of the farmers they interviewed believed that a washing bay was a useful animal biosecurity measure. More generally, other research has found that animal biosecurity practices are unlikely to be undertaken when they are perceived to be too costly, too labour intensive or impractical (Gunn et al., 2008). This is consistent with this research, where interviewees perceived wash bays to be inconvenient, impractical and socially unacceptable.

Beyond the use of wash bays, many interviewees mentioned cost as a reason for not implementing further weed hygiene practices. This is consistent with the research on adoption of weed control more generally, where cost is often cited as a reason for not controlling weeds (Berney et al., 2012; Davis and Carter, 2014), and conversely, costeffectiveness is cited as a reason for implementing integrated weed management (Llewellyn et al., 2004). While considerable research has been invested into calculating the economics of weed control (Morfe and Weiss, 2006; Western Australian Agriculture Authority, 2016), no economic research into the cost-effectiveness of weed hygiene practices was found. Nevertheless, in weed hygiene policy and practice (and in most interviews), the idea that weed hygiene is cheaper than weed control passes as common sense. At least one landholder suggested an alternative view that, on the basis that on-property weed control and expenditure were always required, the extra expense 
of weed hygiene was not necessarily warranted. This raises the question as to what extent the idea that prevention is better than cure always holds up for weed hygiene and, if it does, under what circumstances, for what practices, at what scale, and for what groups (for a related discussion see Auld and Johnson, 2014)?

Another key part of the knowledge-implementation gap related to a lack of intra- and inter-organisational coordination. While some parts of some organisations were committed to weed hygiene, such efforts could be undermined by other staff within the same organisation or other organisations who worked in the same area. In this way weed hygiene, like weed control, presents a collective action problem because it requires many people and organisations to work together. Past research on collective action in the context of weed control indicates that such efforts will only be effective when there are working relationships among most of the individuals and organisations involved (Graham, 2013). Such relationships must be forged first if everyone is to agree on a common goal, commit to individual efforts and then support the efforts of others (Graham and Rogers, 2017). This suggests the importance of considering the social relations that exist around weed hygiene and not just individual endeavours.

Social acceptance of weed hygiene practices as part of the norm of being a 'good land manager' could also be pursued by industry and government groups alike. As Rush (1996) identified, farmers who control weeds have a 'weed ethic' developed through constant vigilance and implementation of integrated weed management practices. Weed control is viewed as a socially responsible practice and correlates highly with farming sub-cultural norms of being a 'good farmer' (Burton, 2004; Vanclay et al., 2006). Therefore, along with fostering collective action, fostering collective farming identities around weed hygiene (alongside control) via the notion that prevention and intervention together are best practice, may be an avenue for realising increased awareness and adoption.

\subsection{Weed hygiene adoption}

There was a small subset of practices for which there was good knowledge and implementation of weed hygiene. Across all groups, this included washing vehicles and 
machinery and providing weed identification guides or supplies to personnel. The washing of vehicles and machinery is not specific to weed hygiene and is adopted because it is part of the quotidian maintenance practices of private landholders, public land managers, weed contractors and transport operators. The lack of importance attached to cleaning vehicles and machinery for weed hygiene reasons is partly explained by Ruttledge et al. (2015), who found that only $4.1 \%$ of landholders surveyed believed that vehicles and machinery were responsible for introducing the weed into their properties. In the context of integrated weed control, Llewellyn et al. (2004) characterise practices that are commonly used but not for weed control as secondary practices. This distinction between primary and secondary practices may also be useful in the context of weed hygiene and understanding to what extent weed hygiene is a genuine consideration or rationale used to allocate resources to biosecurity.

The provision of weed identification guides is a practice that requires little time or resources, which is one of the reasons interviewees offered for why they adopt this practice. The more resource-intensive practice of training staff in weed hygiene was less likely to be implemented by weed contractors and transport operators. This is consistent with other research on biosecurity practices of auxiliary industries, which found that just over half of the organisations approached carry out training (Gunn et al., 2008). It is most likely that this is due to cost and reluctance to spend resources on addressing a problem that companies do not necessarily see as an issue they are responsible for and for which they may perceive they have little influence over. Those organisations that did provide training often relied on materials or training sessions provided by government agencies. This suggests that one way to increase training of weed contractors or transport operators could be through training sessions offered by local councils or agriculture departments. Nonetheless, in view of the constraints on weed hygiene implementation identified here, the nature and purpose of any training and its relationship to other aspects of an organisation's operations would need to be carefully designed. 


\section{Conclusion}

This research builds upon an analysis of weed management and weed hygiene literature that suggested that, while little was known about knowledge and practice of weed hygiene by landholders and others, implementation and knowledge of weed hygiene practices are probably limited. This is despite considerable research and management effort to understand pathways for weed spread and to develop weed hygiene guidelines and policies. For selected groups, this research provides evidence that implementation of weed hygiene practices is patchy at best, that implementation varies across and within sectors and across weed hygiene practices, but that this is not simply due to a lack of knowledge. The reasons for patchy implementation and associated issues of resource availability, inter and intra-organisational coordination, and farm risk assessment suggest further avenues for research that should both test and extend the findings of this research.

While knowledge of weed hygiene practices was generally good except for the transport industry, implementation was not always consistent with the level of knowledge and awareness. This 'gap' between knowledge on the one hand, and behavior on the other, is well known in many areas of social science and human behavior. It has been found in areas including sustainability (Barr, 2008), bushfire preparation (Eriksen and Gill, 2010), and farmer adoption of conservation practices (Pannell et al., 2006), among others. The divergence between knowledge and practice has been traditionally and largely been investigated using quantitative methods. More recently, however, qualitative methods have been used productively to explore the personal, social, family, business, or organizational contexts in which decisions, certain practices, or ways of doing things develop. Such research allows exploration of the 'why' questions regarding adoption or non-adoption and, crucially, expands the framing of the problem beyond the individual to consider the social, cultural, economic and institutional milieu in which they operate (for example see Gill et al., 2015; Shove et al., 2012). The insights from the qualitative data suggest that weed hygiene practices and their implementation or lack thereof are the outcome of similar processes and settings. The relationships that landholders and 
others are part of, and the material settings of farm and other operations are influential in the implementation of weed hygiene.

While this research has considered social aspects of weed hygiene across one jurisdiction (the state of New South Wales) and various groups, it does represent exploratory research on a topic that has attracted little attention, both in Australia and internationally. Given ongoing global, national, and intra-national concerns about biosecurity and the processes by which both weeds and other organisms spread, better understanding the extent to which hygiene practices are implemented and the reasons and rationalities that influence implementation or lack thereof, will be important to developing effective strategies and programs to encourage implementation of hygiene practices. Thus further research into the patchy and inconsistent implementation of weed hygiene practices will be valuable. As discussed above, UK biosecurity research has highlighted the complex networks of communication and relationships that shape biosecurity practice. Similar research would be valuable for weed hygiene.

Overall, this research suggests two general pathways for future weed hygiene research. The first is to examine knowledge and implementation in more depth and in manner that does not presume a knowledge deficit is the key source of non-implementation. Rather, investigation should not only consider the extent of the gap but also the nature or constitution of the gap itself (Eriksen and Gill, 2010). Second, and with a view to policy and practice, research should seek to identify points of leverage or consistency in existing organisational or individual practices, processes, and thinking (see for example Butler et al., 2016), with a view to understanding how broader practices in organisations shape weed hygiene implementation or lack thereof (Shove et al., 2012). More specifically, for particular groups and their relevant weed hygiene practices such research should investigate why some practices that are known about are not adopted while others are; it should explore in more detail the decision process around adopting or not adopting practices, what shapes such decisions, and subsequent timelines of persistence or abandonment of practices - what facilitates or impedes successful and persistent implementation of weed hygiene practices for individuals, landholders, and organisations? 
In organisations, some interviewees reported building weed hygiene into higher level policies and standard procedures, including working across sections. Such examples highlight the role of diverse decision-makers, managers, and operators within organisations and represent capacity and ideas for enhanced weed hygiene management. Future research could ask what can be learned from this insight that might help encourage implementation or develop systems that facilitate weed hygiene implementation as part of broader activities.

Acknowledgements Dr Stephen Johnson from the Department of Primary Industries (NSW DPI) provided feedback on the manuscript. This research project was funded by the NSW DPI Weed Action Program Innovation Grants 2014-2015. Support also came from the ARC Discovery Project DP130102588. Dr Sarah Rogers and Viveka Simpson assisted with the research. 


\section{References}

ACCRC, 2000. Farm Hygiene for Disease and Weed Control. Australian Cotton Cooperative Research Centre, Narrabri

Allen, K., Gartenstein, S., 2010. Keeping It Clean: A Tasmanian Field Hygiene Manual to Prevent the Spread of Freshwater Pests and Pathogens. NRM South, South Hobart

Anderson, C., 2011. Come Clean Go Clean: A Step by Step Guide to Vehicle Wash Down. NSW Department of Primary Industries, Sydney

Anderson, L.G., Rocliffe, S., Haddaway, N.R., Dunn, A.M., 2015. The role of tourism and recreation in the spread of non-native species: A systematic review and meta-analysis. PLoS ONE 10, doi:10.1371/journal.pone.0140833.

Ansong, M., Pickering, C., 2014. Weed seeds on clothing: A global review. J. Environ. Manag. 144, 203211.

Ansong, M., Pickering, C., Arthur, J.M., 2015. Modelling seed retention curves for eight weed species on clothing. Austral Ecol. 40, 765-774.

Aslin, H.J., Kruger, H., Thompson, L.-J., Duncan, A., 2013. Systematic review of Australian weed-related social surveys. Rural Industries Research and Development Corporation, Canberra

Auld, B.A., Johnson, S.B., 2014. Invasive alien plant management. CAB Reviews 9, http://www.cabi.org/cabreviews.

Australian Bureau of Statistics, 2008. Natural resource management on Australian farms 2006-07. Australian Bureau of Statistics, Canberra

Bajwa, A.A., Nguyen, T., Navie, S., O'Donnell, C., Adkins, S., 2018. Weed seed spread and its prevention: The role of roadside wash down. J. Environ. Manag. 208, 8-14.

Baldyga, N., 2006. Machinery Hygiene Guidelines for Roadside Managers: Minimising the Spread of Chilean Needle Grass. Victorian Government Department of Primary Industries, Bacchus Marsh, http://www.weeds.org.au/WoNS/Chileanneedlegrass/docs/Machinery_Hygiene_Guidelines_for _Roadside_Managers.pdf.

Barker, M., 2005. Strategic Analysis and Scoping Study on Human Spread of Weeds. Natural Heritage Trust and Queensland Department of Natural Resources and Mines and Energy, Brisbane, http://www.weeds.org.au/weedspread.htm.

Barr, S., 2008. Environment and Society: Sustainability, Policy and the Citizen. Ashgate, Aldershot.

Baxter, J., Eyles, J., 1997. Evaluating qualitative research in social geography: establishing 'rigour' in interview analysis. T. I. Brit. Geogr. 22, 505-525.

Berney, P.J., Sindel, B.M., Coleman, M.J., Marshall, G.R., Reeve, I.J., Kristiansen, P.E., Year. Improving regional adoption of weed control: a case study. Developing Solutions to Evolving Weed Problems. Proceedings of the 18th Australasian Weeds Conference.

Biosecurity Queensland, 2014. Vehicle and Machinery Checklists: Clean-down Procedures 2014. Department of Agriculture, Fisheries and Forestry, Brisbane, https://www.daf.qld.gov.au/_data/assets/pdf_file/0011/58178/IPA-CleandownProcedures.pdf.

Blanco-Moreno, J.M., Chamorro, L., Masalles, R.M., Recasens, J., Sans, F.X., 2004. Spatial distribution of Lolium rigidum seedlings following seed dispersal by combine harvesters. Weed Res. 44, 375387.

Braun, V., Clarke, V., 2006. Using thematic analysis in psychology. Qualitative Research in Psychology 3, 77-101.

Burton, R., 2004. Seeing Through the 'Good Farmer's' Eyes: Towards Developing an Understanding of the Social Symbolic Value of ‘Productivist' Behaviour. Sociologia Ruralis 44, 195-215. 
Butler, K., Gordon, R., Roggeveen, K., Waitt, G., Cooper, P., 2016. Social Marketing and value in behaviour? Perceived value of using energy efficiently among low income older residents. Journal of Social Marketing 6, 144-168.

Cattanach, G., Harris, A., Horne, J., 2013. Mapping Australia's Weed Management System. Rural Industries Research and Development Corporation, Canberra, https://rirdc.infoservices.com.au/items/13-019.

CCF, 2011. A Guide for Machinery Hygiene for Civil Construction. Civil Contractors Federation, Hawthorn

Chalak, M., Pannell, D.J., 2012. Optimising control of an agricultural weed in sheep-production pastures. Agric. Syst. 109, 1-8.

Coleman, M.J., Sindel, B.M., Van Der Meulen, A.W., Reeve, I.J., 2011. The risks associated with weed spread in Australia and implications for natural areas. Nat. Areas J. 31, 368-376.

Cooke, B., Lane, R., 2015. How do amenity migrants learn to be environmental stewards of rural landscapes? Landscape Urban Plan. 134, 43-52.

D'Emden, F., Bell, G., Llewellyn, R., 2004. Rural landholder attitudes towards the responsibilities and action for managing declared weeds in Western Australia. Plant Prot. Quart. 19, 147-150.

Davis, D., Carter, J., 2014. Finding common ground in weed management: peri-urban farming, environmental and lifestyle values and practices in southeast Queensland, Australia. Geogr. J. $180,342-352$.

de Hayr, B., 2013. 2013 National Landcare Survey Results. Landcare Australia Sydney, http://www.landcareonline.com.au/?page_id=14449.

Department of Environment and Primary Industries, 2010. Biosecurity Implementation Plan 2010 to 2013. Biosecurity Victoria, Melbourne, http://www.depi.vic.gov.au/_data/assets/pdf_file/0020/254234/Biosecurity_Strategy_Implem entation_Plan_230910.pdf.

Department of Primary Industries, 2013. NSW Biosecurity Strategy 2013-2021. NSW Department of Primary Industries, Sydney, http://www.dpi.nsw.gov.au/biosecurity/biosecurity-strategy.

Department of Primary Industries and Fisheries, 2008. Queensland Biosecurity Strategy 2009-14. Queensland Department of Primary Industries and Fisheries, Brisbane, http://rti.cabinet.qld.gov.au/documents/2008/dec/biosecurity\%20strategy/Attachments/QldBiosecurityStrategy-2009-14.pdf.

DNRME, 2004. Prickly Acacia: National Case Studies Manual. Queensland Government Department of Natural Resources, Mines and Energy, Cloncurry, http://www.weeds.org.au/WoNS/pricklyacacia/docs/Prickly_Acacia_Mgmnt-5.pdf.

DoE, 2015. Arrive Clean, Leave Clean: Guidelines to help prevent the spread of invasive plant diseases and weeds threatening our native plants, animals and ecosystems. Australia Government Department of the Environment, Canberra

Dorea, F.C., Berghaus, R., Hofacre, C., Cole, D.J., 2010. Survey of Biosecurity Protocols and Practices Adopted by Growers on Commercial Poultry Farms in Georgia, U. S. A. Avian Dis. 54, 1007-1015.

DPIPW\&E, 2015. Weed and Disease Planning and Hygiene Guidelines: Preventing the Spread of Weeds and Diseases in Tasmania. Department of Primary Industries, Parks, Water and Environment, Hobart

Eriksen, C., Gill, N., 2010. Bushfire and everyday life: Examining the awareness-action 'gap' in changing rural landscapes. Geoforum 41, 814-825.

Food and Agriculture Organisation, 2007. FAO Biosecurity Toolkit. Food and Agriculture Organisation, Rome. 
Gardener, M.R., Whalley, R.D.B., Sindel, B.M., 2003. Ecology of Nassella neesiana, Chilean needle grass, in pastures on the Northern Tablelands of New South Wales I. Seed production and dispersal. Aust. J. Agric. Res. 54, 613-619.

Gill, N., Osman, P., Head, L., Voyer, M., Harada, T., Waitt, G., Gibson, C., 2015. Looking beyond installation: Why households struggle to make the most of solar hot water systems. Energy Policy 87, 83-94.

Graham, S., 2013. Three cooperative pathways to solving a collective weed management problem. Aust. J. Env.Manag. 20, 116-129.

Graham, S., 2014. A new perspective on the trust power nexus from rural Australia. J. Rural Stud. 36, 8798.

Graham, S., Gill, N., Cross, R., Simpson, V., Taylor, E., Rogers, S., 2016. Weed hygiene practices in NSW: Knowledge and practices of landholders, public land managers, weed contractors and agricultural transport operators. University of NSW, Sydney, http://ro.uow.edu.au/sspapers/2536/.

Graham, S., Rogers, S., 2017. How Local Landholder Groups Collectively Manage Weeds in South-Eastern Australia. Environ. Manag. 60, 396-408.

GRDC, 2014. Integrated Weed Management in Australian Cropping Systems. In: Storrie, A. (ed). Grains Research and Development Corporation, Canberra

Grech, C.J., McLaren, D.A., Lowien, J., McWhirter, L., Butler, K.L., Sindel, B.M., 2014. Assessment of management options for Chilean needle grass in sheep-grazing systems. Grass Forage Sci 69, 119-128.

Gunn, G.J., Heffernan, C., Hall, M., McLeod, A., Hovi, M., 2008. Measuring and comparing constraints to improved biosecurity amongst GB farmers, veterinarians and the auxiliary industries. Prev. Vet. Med. 84, 310-323.

Head, L., 2017. The social dimensions of invasive plants. Nature Plants 3, nplants 201775.

Head, L., Larson, B.M., Hobbs, R., Atchison, J., Gill, N., Kull, C., Rangan, H., 2015. Living with Invasive Plants in the Anthropocene: The Importance of Understanding Practice and Experience. Conservation and Society 13, 311-318.

Heffernan, C., Nielsen, L., Thomson, K., Gunn, G., 2008. An exploration of the drivers to bio-security collective action among a sample of UK cattle and sheep farmers. Prev. Vet. Med. 87, 358-372.

Hinchliffe, S., Bingham, N., 2008. Securing Life: The Emerging Practices of Biosecurity. Environ. Plan. A 40, 1534-1551.

Hoe, F.G.H., Ruegg, P.L., 2006. Opinions and Practices of Wisconsin Dairy Producers About Biosecurity and Animal Well-Being. J. Dairy Sci. 89, 2297-2308.

Hoffmann, B.D., Broadhurst, L.M., 2016. The economic cost of managing invasive species in Australia. Neobiota 31, 1-8.

Hulme, P.E., Bacher, S., Kenis, M., Klotz, S., Kühn, I., Minchin, D., Nentwig, W., Olenin, S., Panov, V., Pergl, J., Pyšek, P., Roques, A., Sol, D., Solarz, W., Vilà, M., 2008. Grasping at the routes of biological invasions: A framework for integrating pathways into policy. J. Appl, Ecol. 45, 403-414.

Huwer, R.K., Briese, D.T., Dowling, P.M., Kemp, D.R., Lonsdale, W.M., Michalk, D.L., Neave, M.J., Sheppard, A.W., Woodburn, T.L., 2005. Can an integrated management approach provide a basis for long-term prevention of weed dominance in Australian pasture systems? Weed Res. 45, 175-192.

Invasive Plants and Animals Committee, 2016. Australian Weeds Strategy 2017 to 2027: consultation draft. Australian Government Department of Agriculture and Water Resources, Canberra.

Klepeis, P., Gill, N., Chisholm, L.A., 2009. Emerging amenity landscapes: Invasive weeds and land subdivision in rural Australia. Land Use Policy 26, 380-392. 
Korstjens, I., Moser, A., 2018. Series: Practical guidance to qualitative research. Part 4: Trustworthiness and publishing. European Journal of General Practice 24, 120-124.

Lestari, V., Sirajuddin, S., Kasim, K., 2011. Adoption of biosecurity measures by layer smallholders. J. Indo. Trop. Anim. Agric. 36, 297-302.

Lincoln, Y.S., Guba, E.G., 1985. Naturalistic Inquiry. Sage Publications, California.

Llewellyn, R.S., Lindner, R.K., Pannell, D.J., Powles, S.B., 2004. Grain grower perceptions and use of integrated weed management. Aust. J. Exp. Agric. 44, 993-1001.

Llewellyn, R.S., Lindner, R.K., Pannell, D.J., Powles, S.B., 2007. Herbicide resistance and the adoption of integrated weed management by Western Australian grain growers. Agric. Econ. 36, 123-130.

Local Land Services, 2017. NSW weed reforms. In. http://www.Ils.nsw.gov.au/biosecurity/weed-control Accessed: 11 August 2017

Lonsdale, W.M., Lane, A.M., 1994. Tourist vehicles as vectors of weed seeds in Kakadu National Park, Northern Australia. Biol. Conserv. 69, 277-283.

Ma, Z., Clarke, M., Church, S.P., 2018. Insights into individual and cooperative invasive plant management on family forestlands. Land Use Policy.

McKiernan, S., 2017. Managing invasive plants in a rural-amenity landscape: the role of social capital and Landcare. Journal of Environmental Planning and Management, 1-19.

Moerkerk, M., Year. Risk of weed movement through vehicles, plant and equipment: results from a Victorian study. Fifteenth Australian Weeds Conference, Adelaide.

Morfe, T.A., Weiss, J., Year. Optimising government investment at different stages of the weed invasion process. Proceedings of the 15th Australian Weeds Conference. Adelaide: Weed Management Society of South Australia.

National Weed Spread Prevention Committee, 2006. National Weed Spread Prevention Draft Action Plan. Queensland Government Department of Natural Resources, Mines and Water, Brisbane

Natural Resources Commission, 2014. Weeds - Time to get serious: Review of weed management in NSW, Final report and recommendations. Natural Resources Commission, Sydney.

Neale, J., 2016. Iterative categorization (IC): a systematic technique for analysing qualitative data. Addiction 111, 1096-1106.

Nikman, S.R., Moekerk, M., Cousens, R., Year. Weed seed contamination in cereal and pulse crops. Thirteenth Australian Weeds Conference, Perth.

Pannell, D., Marshall, G., Barr, N., Curtis, A., Vanclay, F., Wilkinson, R., 2006. Understanding and Promoting adoption of Conservation technologies by Rural Landholders. Australian Journal of Experimental Agriculture 46, 1407-1424.

Patton, M., 2002. Qualitative Research and Evaluation Methods, 3rd ed. Sage, Newbury Park.

Pejchar, L., Mooney, H.A., 2009. Invasive species, ecosystem services and human well-being. Tr. Ecol. Evol. 24, 497-504.

PHA, 2011. Farm Biosecurity Manual for the Grains Industry. Plant Health Australia, Canberra, http://www.farmbiosecurity.com.au/toolkit/plans-manuals/.

PHA, 2012. Farm Biosecurity Manual for the Cotton Industry. Queensland Department of Agriculture, Fisheries and Forestry, Brisbane, http://www.farmbiosecurity.com.au/toolkit/plans-manuals/.

Pickering, C.M., Mount, A., Wichmann, M.C., Bullock, J.M., 2011. Estimating human-mediated dispersal of seeds within an Australian protected area. Biol. Invasions 13, 1869-1880.

Pimentel, D., Zuniga, R., Morrison, D., 2005. Update on the environmental and economic costs associated with alien-invasive species in the United States. Ecological Economics 52, 273-288.

Reeve, I.J., Coleman, M.J., Sindel, B.M., 2015. Factors influencing rural landholder support for a mandated weed control policy. Land Use Policy 46, 314-323. 
Rudman, T., Tucker, D., French, D., 2004. Washdown Guidelines for Weed and Disease Control - Edition 1. Tasmanian Government Department of Primary Industries, Water and Environment, Hobart, http://dpipwe.tas.gov.au/invasive-species/weeds/weed-hygiene/washdown-guidelines.

Rush, D., Year. A practicioner's perspective of weed management in pasture systems. Proceedings of the 11th Australian Weeds Conference, Melbourne, Australia, 30 September-3 October 1996, Weed Science Society of Victoria Inc.

Ruttledge, A., Whalley, R.D.B., Reeve, I.J., Backhouse, D.A., Sindel, B.M., 2015. Preventing weed spread: A survey of lifestyle and commercial landholders about Nassella trichotoma in the Northern Tablelands of New South Wales, Australia. Rangel. J, 27, 409-423.

Sayers, R.G., Good, M., Sayers, G.P., 2014. A survey of biosecurity-related practices, opinions and communications across dairy farm veterinarians and advisors. Vet.. J. 200, 261-269.

Secomb, N., Year. Defining the distribution of branched broomrape (Orobanche ramosa L.) by tracing the movement of potential vectors for the spread of seed. Fifteenth Australian Weeds Conference, Adelaide.

Shove, E., Pantzar, M., Watson, M., 2012. The Dynamics of Social Practice: Everyday Life and How it Changes. Sage, London.

Sindel, B.M., Berney, P., Coleman, M.J., Marshall, G., Reeve, I.J., 2013. Improved regional adoption of weed control: A case study in the NSW Northern and Southern Tablelands. Australian Government Rural Industries Research and Development Corporation, Canberra

Sindel, B.M., Coleman, M.J., 2010. Weed Detection and Control on Small Farms: A Guide for Owners. University of New England, Armidale

Sindel, B.M., Coleman, M.J., 2012. Fireweed: A Best Practice Management Guide for Australian Landholders. University of New England, Armidale

Van Der Meulen, A.W., Reeve, I.J., Sindel, B.M., 2007. Weed management on grazing properties: A survey of livestock producers in New South Wales and Victoria. Aust. J. Exp. Agric. 47, 14151421.

Vanclay, F., Howden, P., Mesiti, L., Glyde, S., 2006. The social and intellectual construction of farming styles: Testing Dutch ideas in Australian agriculture. Sociologia Ruralis 46, 61-82.

Weiss, F., Brummer, T.J., Pufal, G., 2016. Mountain bikes as seed dispersers and their potential socioecological consequences. J. Environ. Manag. 181, 326-332.

Western Australian Agriculture Authority, 2016. Western Australian Biosecurity Strategy 2016-2025. Western Australian Agriculture Authority, Perth. 
Supplementary Data Weed hygiene practices known and 'always' or 'very often' implemented by private landholders, public land managers, weed contractors and agricultural transport operators interviewed.

\begin{tabular}{lcc}
\hline Weed hygiene practices: Private landholders $(\mathbf{n = 1 7})$ & Known & Implemented \\
\hline Wash bays for machinery & 14 & 11 \\
Wash bays for vehicles & 13 & 5 \\
Minimise lending of equipment & 14 & 10 \\
Check machinery before relocation & 12 & 5 \\
Clean borrowed equipment & 12 & 10 \\
Provide weed hygiene supplies for personnel & 10 & 10 \\
Request vendor declarations for new stock $(\mathrm{n}=11)$ & 9 & 9 \\
Quarantine stock in a dedicated yard $(\mathrm{n}=11)$ & 9 & 7 \\
Request vendor declarations for bought seed $(\mathrm{n}=7)$ & 6 & 6 \\
Keep records of seeds and source $(\mathrm{n}=8)$ & 8 & 8 \\
Enforce machinery standards for contractors & 10 & 3 \\
Restrict access to farm & 5 & 5 \\
Avoid vehicle/machinery movements during wet periods & 9 & 8 \\
Use wash baths for equipment, clothes, footwear & 6 & 1 \\
\hline
\end{tabular}

\begin{tabular}{lcc}
\hline Weed hygiene practices: Public land managers (n=15) & Known & Implemented \\
\hline Staff use wash bays for machinery & 14 & 8 \\
Staff use wash bays for vehicles & 14 & 10 \\
Staff use wash baths for equipment, clothes, footwear & 13 & 5 \\
Staff check machinery and equipment before a job & 14 & 10 \\
Train staff in weed hygiene & 13 & 7 \\
Provide weed identification guides for staff & 14 & 13 \\
Weed hygiene clause in contracts & 12 & 6 \\
Weed ID guides for contractors & 13 & 11 \\
Contractors use wash bays for machinery & 14 & 5 \\
Contractors use wash bays for vehicles & 14 & 4 \\
Contractors use wash baths for equipment, clothes and footwear & 14 & 2 \\
\hline
\end{tabular}

\begin{tabular}{lcc}
\hline Weed hygiene practices: Weed contractors (n=12) & Known & Implemented \\
\hline Weed hygiene clause in contracts & 8 & 2 \\
Provide weed identification guides for staff & 11 & 8 \\
Train staff in weed hygiene & 10 & 6 \\
Wash bays for machinery & 12 & 7 \\
Wash bays for vehicles & 11 & 6 \\
Use wash baths for equipment, clothes, footwear & 11 & 3 \\
Minimise machinery movement and slashing during peak seed times & 5 & 4 \\
(roadside work) (n=7) & 4 & 3 \\
Work from clean to infested areas (roadside work) (n=6) & 4 & 5 \\
Avoid wearing felt-soled boots and waders (waterways) (n=8) & 8 & 3 \\
Disinfect footwear, equipment and machinery between sites & & \\
(waterways) (n=8) & &
\end{tabular}

\begin{tabular}{lcc}
\hline Weed hygiene practices: Transport operators $(\mathbf{n}=\mathbf{1 0})$ & Known & Implemented \\
\hline Weed hygiene clause in contracts & 2 & 1 \\
Provide weed identification guides for staff & 5 & 3 \\
Train staff in weed hygiene & 6 & 2 \\
Wash bays for vehicles & 9 & 8 \\
Use wash baths for equipment, clothes, footwear & 5 & 4 \\
Check machinery and equipment is dry and free of debris & 8 & 7
\end{tabular}


The difference between the number of interviewees ( $n$ ) and the number who implement the practice is those who said they 'sometimes', 'rarely', or 'never' implemented a practice. In this table we excluded those who 'sometimes' implemented a practice on the grounds that 'sometimes' implementing a weed hygiene practice represents practice that is likely to contribute to weed spread. 